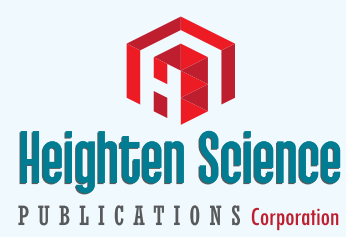

ISSN

2640-2858
*Address for Correspondence: Stefano Ardu, Division of Cariology and Endodontology, Section of Dental Medicine, Faculty of Medicine, University of Geneva, Geneva, Switzerland, Tel: 02238291 50/65;

Email: stefano.ardu@unige.ch

Submitted: 05 July 2018

Approved: 24 July 2018

Published: 25 July 2018

Copyright: @2018 Duc 0, et al. This is an open access article distributed under the Creative Commons Attribution License, which permits unrestricted use, distribution, and reproduction in any medium, provided the original work is properly cited

Check for updates
Research Article

\section{Staining susceptibility of recently developed resin composite materials}

\author{
Olivier Duc ${ }^{1}$, Emilie Betrisey ${ }^{1}$, Enrico Di Bella ${ }^{2}$, Ivo Krejci ${ }^{1}$ and \\ Stefano Ardu ${ }^{1 *}$ \\ 'Division of Cariology and Endodontology, Section of Dental Medicine, Faculty of Medicine, \\ University of Geneva, Geneva, Switzerland \\ ${ }^{2}$ Department of Economics and Quantitative methods, University of Genoa, Genoa, Italy
}

\section{Abstract}

Objectives: To evaluate the colour stability of 3 recently developed resin based materials continuously exposed to various staining agents.

Methods: 144 disc-shaped specimens were made of each of the 3 tested composites (Essentia, Brillant, Inspiro). Half of them were of $1 \mathrm{~mm}$ thickness, the other half $1.2 \mathrm{~mm}$ thickness. The thicker group was than polished up to 4000 grit and reduced to $1 \mathrm{~mm}$ thickness, too. All specimens after $24 \mathrm{~h}$ dry storage in an incubator (INP-500, Memmert), received an initial colour measurement by means of a calibrated reflectance spectrophotometer (SpectroShade, MHT, Niederhasli, Switzerland). Specimens were then divided into 6 groups $(n=6)$ and immersed in 5 staining solutions or artificial saliva (control). All specimens were kept in an incubator at $37^{\circ} \mathrm{C}$ for 28 days. Staining solutions (red wine, curry mixed water, curry mixed oil, tea and coffee) were changed every 7 th day to avoid bacteria or yeast contamination. After 28 days of storage spectrophotometric measurements were repeated and $L^{*}{ }^{*}{ }^{*}{ }^{*}$ scores once more recorded to determine the colour $(\triangle \mathrm{E} 00)$ changes.

Results: All tested materials showed significant color changes after 28 days staining immersion.

When considered over a black background $\triangle \mathrm{E} 00$ of polished samples varied from 1.7 (Brillant/ distilled water) to 24.1 (Brillant/wine).

When considered over a white background $\triangle \mathrm{E} 00$ of polished samples varied from 1.1 (Essentia/ distilled water) to 32.5 (Inspiro/wine).

When considered over a black background $\triangle E 00$ of unpolished samples varied from 1.1 (Essentia, Inspiro/distilled water) to 25.8 (Essentia/wine).

When considered over a white background $\triangle \mathrm{E} 00$ of unpolished samples varied from 1.4(Inspiro/ distilled water) to 33.1 (Inspiro/wine).

Conclusions: Staining of restorative materials seems to be dependent on the composition of the product itself. Unpolished samples demonstrated to be more prone to staining than the polished ones.

\section{Introduction}

Resin composites are widely used worldwide due to their capacity of easily reproducing tooth like appearance [1-3]. Their use allows for a minimal invasive dentistry which imply lower cost if compared to the more invasive prosthetic approach based on ceramic crowns thus it is preferred by the majority of patients. Furthermore adhesive dentistry is less time consuming and do not require dental technician intervention.

Anyway, some disadvantages are evident when comparing resin composites to ceramics: gloss retention is lower over time and they have a much higher staining susceptibility $[4,5]$. Specifically, resin composite staining potential is a hot topic in today's research [6-15] because it can furnish precious long-term data on restoration's behavior to the practitioners. 
So far, no consensus was found if polishing was detrimental or advantageous for composite staining resistance and how results present in literature can be compared. Furthermore the presence of polished and unpolished part of a restoration is a common clinical situation and it is of interest to investigate how the different surfaces will react to staining agents. Class II, III and IV restored by means of resin composites have always the contact surface unpolished while the rest of the mass is mainly polished.

The aim of this study was to evaluate, in vitro, the staining potential of recently developed resin composites submitted to different food coloring liquids with or without surface polishing. The obtained data could be predictive of "in vivo" medium term clinical behavior.

The first hypothesis tested was that the materials included into the study do not significantly change their colour after 4 weeks immersion in the staining solutions.

The second hypothesis was that resin composite polishing does not significantly influence their staining susceptibility.

\section{Materials and Methods}

A total of 72 disc-shaped specimens were made of each of the 3 tested composites (Essentia, Brillant, Inspiro). Their technical data are summarized in Table 1. All samples were light cured for $20 \mathrm{~s}$ at a distance of $1 \mathrm{~mm}$ with a LED curing device (Valo, Ultradent, South Jordan, USA) used in "standard mode" with a power density of $>1000 \mathrm{~mW} / \mathrm{cm}^{2}$ (checked by LED Demetron radiometer 910726 , Kerr Corporation Middleton, USA). Half of them were of $1 \mathrm{~mm}$ thickness, the other half $1.2 \mathrm{~mm}$ thickness. The thicker group was than polished with 500-, 1200-, 2400- and 4000- grit SiC abrasive paper and reduced to $1 \mathrm{~mm}$ thickness, too. Polishing was performed for $60 \mathrm{~s}$ for each grit of abrasive paper under continuous water cooling at a constant force of $2 \mathrm{~N}$, according to the methodology proposed by Ardu et al. [16] and as carried out in previous studies $[17,18]$. After $24 \mathrm{~h}$ dry storage in an incubator (INP-500, Memmert), all specimens received an initial colour measurement by means of a calibrated reflectance spectrophotometer (SpectroShade, MHT, Niederhasli, Switzerland). Specimens were then divided in 6 groups $(\mathrm{n}=6)$ and immersed in 5 staining solutions or artificial saliva (control). All specimens were kept in an incubator at $37^{\circ} \mathrm{C}$ for 28 days. Staining solutions (red wine, curry mixed water, curry mixed oil, tea and coffee) were changed every 7 th day to avoid bacteria or yeast contamination. The details of staining solutions are summarized in Table 2 . After 28 days of storage samples were

\begin{tabular}{|c|c|c|c|c|c|c|}
\hline Composite & Composition & Manufacturer & $\begin{array}{l}\text { Lot and } \\
\text { expiring } \\
\text { date }\end{array}$ & $\begin{array}{l}\text { Filler } \% \\
\text { by weight }\end{array}$ & $\begin{array}{c}\text { Filler \% by } \\
\text { volume }\end{array}$ & $\begin{array}{c}\text { Water } \\
\text { sorption } \mu \mathrm{m} / \\
\mathrm{mm}^{3}\end{array}$ \\
\hline $\begin{array}{c}\text { Essentia } \\
\text { (dentin) }\end{array}$ & $\begin{array}{c}\text { MD dentin } \\
\text { (Universal restorative } \\
\text { radiopaque) } \\
\text { UDMA, Bis-MEPP, Silicon } \\
\text { Dioxide, Fluoro-alumino- } \\
\text { silicate glass }\end{array}$ & $\begin{array}{l}\text { GC Corporation, } \\
\text { Tokyo Japan }\end{array}$ & $\begin{array}{c}\text { Lot: } \\
1511201 \\
2018-11\end{array}$ & 76 & 63 & Not available \\
\hline $\begin{array}{l}\text { Brillant } \\
\text { Everglow } \\
\text { (body) }\end{array}$ & \begin{tabular}{|c|} 
A2/B2 body \\
(Submicron hybrid \\
universal) \\
Aluminum Barium Silicate, \\
Zinc oxide, Bis GMA based \\
resins
\end{tabular} & $\begin{array}{c}\text { Coltene-Whaledent, } \\
\text { Altstätten, } \\
\text { Switzerland }\end{array}$ & $\begin{array}{c}\text { Lot: } \mathrm{G} 27377 \\
2017-06\end{array}$ & 79 & 64 & 15.1 \\
\hline $\begin{array}{c}\text { Inspiro SN } \\
\text { (enamel) }\end{array}$ & $\begin{array}{c}\text { Enamel Skin Neutral } \\
\text { (Nano-hybrid) } \\
\text { Dental glass, silicon } \\
\text { dioxide, Bis GMA based } \\
\text { dental resins }\end{array}$ & $\begin{array}{l}\text { Edelweiss-Whaledent } \\
\text { DR, Zug, Switzerland }\end{array}$ & $\begin{array}{c}\text { Lot: } 750602 \\
2018-11\end{array}$ & 82 & 65 & 20.0 \\
\hline
\end{tabular}




\begin{tabular}{|c|c|}
\hline Table 2: Staining solutions used. \\
\hline Staining Solution & Manufacturer \\
\hline Artificial Saliva (control) & Glandosane solution Helvelpharm, Frauenfeld, Switzerland \\
\hline Tea & English breakfast Twinings, London UK \\
\hline Coffee & Nespresso ristretto, Nestlé Orbe, CH \\
\hline Red Wine & Curry COOP Basel Switzerland \\
\hline Curry with water & Curry COOP Basel Switzerland and \\
\hline Curry with oil & Oil Isio 4 Lesieur, Asnieres sur Seine, France \\
\hline Water & Tap water \\
\hline
\end{tabular}

cleaned for $60 \mathrm{~s}$ with a high pressure-hot water airbrush $\left(0,4 \mathrm{MPa}, 135^{\circ} \mathrm{C}\right.$, Minivapor 93, Effegi Brega s.r.l., 29010 Sarmato, PC- Italy) and air dried. Spectrophotometric measurements were repeated and $\mathrm{L}^{*} \mathrm{a}^{*} \mathrm{~b}^{*}$ scores once more recorded to determine the colour changes according to the classical $\Delta \mathrm{E} 00$ formula.

All the details of the methodology employed in this study were widely explained in a precedent publication [16].

Statistical analysis was performed by means of Anova after testing data by means of Kolmogorov-Smirnov test in order to investigate the effect of the staining solutions (first goal of the paper). Polished and unpolished values of each resin composite were analyzed by means of Fisher's LSD post-hoc test to check if all composites performed in the same way when faced to different staining solution or if their composition could influence their behavior.

Finally all staining values were pooled together per composite and divided in polished or unpolished samples and the $\triangle \mathrm{E} 00$ values were submitted to Fisher's LSD post-hoc test in order to test if polishing had an influence on staining results (second goal of the paper).

\section{Results}

The results are summarized in Table 3.

All tested materials showed significant colour changes $(\mathrm{p}<0.01)$ after 28 days staining immersion.

When considered over a black background $\Delta \mathrm{E} 00$ of polished samples varied from 1.7 (Brillant/distilled water) to 24.1 (Brillant/wine).

When considered over a white background $\Delta \mathrm{E} 00$ of polished samples varied from 1.1 (Essentia/distilled water) to 32.5 (Inspiro/wine).

When considered over a black background $\Delta \mathrm{E} 00$ of unpolished samples varied from 1.1 (Essentia, Inspiro/distilled water) to 25.8 (Essentia/wine).

When considered over a white background $\Delta \mathrm{E} 00$ of unpolished samples varied from 1.4(Inspiro/distilled water) to 33.1 (Inspiro/wine).

When all staining solutions' means of polished samples were pooled together and analyzed over a black background, mean $\Delta \mathrm{E} 00$ values varied from 11.7 (Essentia) to 16.3 (Inspiro) while over a white background were 12.6 (Essentia) to 21.9 (Inspiro).

When all staining solutions' means of unpolished samples were pooled together and analyzed over a black background, mean $\Delta \mathrm{E} 00$ values varied from 17.7 (Essentia) to 21.5 (Inspiro) while over a white background were 16.3 (Essentia) to 23.8 (Inspiro).

Finally, the Fisher's LSD post-hoc test found that polishing had an influence on staining results by lowering their staining susceptibility. 


\begin{tabular}{|c|c|c|c|c|c|c|c|c|c|c|c|c|c|}
\hline \multirow[b]{2}{*}{ Background } & \multirow[b]{2}{*}{ Staining } & \multicolumn{3}{|c|}{ Medians DE00 - Polished } & \multicolumn{3}{|c|}{ Medians DEO0 - Unpolished } & \multicolumn{3}{|c|}{ Grouping Polished } & \multicolumn{3}{|c|}{ Grouping Unpolished } \\
\hline & & Essentia & Brillant & Inspiro & Essentia & Brillant & Inspiro & Essentia & Brillant & Inspiro & Essentia & Brillant & Inspiro \\
\hline Black & Control & 2.4 & 1.7 & 1.8 & 1.1 & 1.6 & 1.1 & $A$ & $A$ & $A$ & $A$ & $A$ & $A$ \\
\hline Black & Tea & 3.0 & 4.1 & 7.0 & 5.6 & 4.1 & 7.3 & $A$ & $A$ & C & B & $A$ & C \\
\hline Black & Coffee & 14.7 & 17.8 & 22.6 & 22.3 & 21.2 & 24.3 & $A$ & B & C & B & $A$ & C \\
\hline Black & Red Wine & 20.9 & 24.1 & 23.1 & 25.8 & 31.7 & 23.0 & A & $\mathrm{C}$ & $\mathrm{C}$ & B & $\mathrm{C}$ & $A$ \\
\hline Black & Curry w/Water & 16.7 & 16.1 & 22.0 & 20.3 & 19.0 & 25.5 & $A$ & $A$ & C & $B$ & $A$ & $\mathrm{C}$ \\
\hline Black & Curry w/Oil & 11.4 & 8.8 & 14.9 & 16.1 & 17.0 & 21.1 & B & A & C & A & A & C \\
\hline Black & All together & 11.7 & 12.6 & 16.3 & 17.7 & 18.1 & 21.5 & A & A & C & A & B & C \\
\hline White & Control & 1.1 & 1.5 & 1.6 & 1.5 & 2.3 & 1.4 & $A$ & $A$ & $A$ & $A$ & $A$ & $A$ \\
\hline White & Tea & 5.1 & 5.5 & 11.2 & 5.7 & 6.2 & 9.6 & $A$ & $A$ & $\mathrm{C}$ & $A$ & $A$ & $\mathrm{C}$ \\
\hline White & Coffee & 19.9 & 22.9 & 30.6 & 22.7 & 25.9 & 25.8 & $A$ & B & C & $A$ & C & C \\
\hline White & Red Wine & 28.7 & 30.4 & 32.5 & 29.9 & 36.5 & 33.1 & $A$ & $\mathrm{~B}$ & C & $A$ & C & B \\
\hline White & Curry w/Water & 16.3 & 17.7 & 25.5 & 19.0 & 17.6 & 27.2 & $A$ & $A$ & C & B & $A$ & C \\
\hline White & Curry w/Oil & 9.8 & 11.5 & 19.0 & 13.5 & 16.2 & 21.7 & $A$ & $A$ & C & $A$ & B & $\mathrm{C}$ \\
\hline White & All together & 12.6 & 14.7 & 21.9 & 16.3 & 16.9 & 23.8 & A & B & C & A & B & C \\
\hline
\end{tabular}

\section{Discussion}

Different factors do influence staining of resin based materials: insufficient polymerization time, surface roughness and diet [19-50]. We aimed to investigate this latter in this in vitro study. Specifically we selected some of the most staining beverages such as tea, coffee, red wine and curry mixed to water or oil. Specifically we decided to investigate a spice like curry, which is widely used in eastern countries, and have an evident staining potential. We even decided to mix it alternatively with water or oil (according to different food recipes) in order to see if some differences could be seen. On the other hand, we maintained, according to previous studies [40,51] artificial saliva (Glandosan ${ }^{\circledR}$, Helvepharm AG, Frauenfeld, Switzerland) as a control.

The second aim of the study was to investigate if surface polishing could have an influence on staining potential of the tested resins. Literature [41-43] is, in fact, not univocal on this point. The choice of 28 days of immersion in the staining solutions was done in order to be consistent with the most recent literature reviews $[45,46]$ representing around 2.5 years of clinical service. The spectrophotometric measurements with a black and a white background were done in order to simulate different clinical conditions such as class IV restorations and class III with no tooth substance is remaining (black background), or class I,II,III with some remaining tooth substance and veneers (white background) [52].

In this study, red wine had the most staining potential, followed by coffee (when considered over a white background) or curry mixed with water (when considered over a black background) and tea. The low $\mathrm{pH}$ of 4.5 of the red wine used in this study and its relatively high level of tannins may serve as an explanation for its high staining capacity, especially if compared to the coffee brewed in "lungo" mode. These results are in line with the precedent study done on unpolished samples [40]. It is of interest to underline the quite high staining potential of curry only when mixed with water. Whenever was mixed with oil, in fact, its staining potential was sensibly lowered. This can be due to his insolubility in oil thus oil can have acted as a staining protector by covering resin composite surface not allowing a direct contact by curcuma particles with the surface.

Generally Essentia showed the best results in the study followed by Brillant and Inspiro, independent of the background. Not much is said by manufacturers on their exact composition which enhance difficulties in results interpretation. Even if filler percentage in volume and weight is, substantially, the same in the 3 tested materials, differences exist in their basic chemical composition. Essentia is based on UDMA chemistry, which is a hydrophobic monomer, this fact, can be one of the key factor of his good performance. 
On the other hand even a small percentage of TegDMA higher in Inspiro than in Essentia (Brillant doesn't contain it) could explain his higher staining values when faced with high polarity molecules as tea and curry mixtures. Moreover, the results of Inspiro might be the consequence of its relatively high translucency, which may accentuate the perceptibility of staining. In general, the influence of the background on the ranking of the materials tested was low. When small differences were present, they were explainable by the different degree of transparence of the material. Generally all values obtained on white background were always higher than the ones obtained on black background.

It is important to state that the staining susceptibility of composite unpolished surfaces were around $30 \%$ higher, showing a higher discoloration potential of samples without polishing in comparison to samples with polishing. This is easily explainable by the possible effect of the free radicals present onto the surface which could react with staining molecules of the tested solutions. The small colour variations obtained with artificial saliva could be due to a natural ageing of the materials and can be related to the relatively low $\mathrm{pH}$ of our Glandosan solution (5.5), different artificial saliva composition could lead to dissimilar results and it could worth to test it.

\section{Conclusion}

Both hypotheses of the study were rejected. All resin composites tested showed significant changes in colour after 4 weeks of immersion in staining solutions. Polishing significantly decreases staining susceptibility of the resin composites. Under the conditions of this in vitro experiment, Essentia best performed in terms of resistance to staining. Clinical studies should confirm these observations in vivo.

\section{Conflict of interest}

The Authors of the manuscript "Staining susceptibility of recently developed resin composite materials" declare they havo no conflict of interest and disclose all relationships or interests that could have direct or potential influence or impart bias on the work.

\section{References}

1. Spreafico RC, Krejci I, Dietschi D. Clinical performance and marginal adaptation of class II direct and semidirect composite restorations over 3.5 years in vivo. J Dent. 2005; 33: 499-507. Ref.: https://tinyurl.com/ya8urxkk

2. Lander E, Dietschi D. Endocrowns: a clinical report. Quintessence Int. 2008; 39: 99-106. Ref.: https://tinyurl.com/ycqd4p5u

3. Dietschi D. Optimising aesthetics and facilitating clinical application of free-hand bonding using the 'natural layering concept'. Br Dental J. 2008; 23: 181-185. Ref.: https://tinyurl.com/ya6ngvtx

4. Pastila $\mathrm{P}$, Lassila LV, Jokinen $\mathrm{M}$, Vuorinen $\mathrm{J}$, Vallittu PK, et al. Effect of short-term water storage on the elastic properties of some dental restorative materials--A resonant ultrasound spectroscopy study. Dent Mater. 2007; 23: 878-884. Ref.: https://tinyurl.com/yclzz3cv

5. Morena R, Beaudreau GM, Lockwood PE, Evans AL, Fairhurst CW. Fatigue of dental ceramics in a simulated oral environment. J Dent Res. 1986; 65: 993-997. Ref.: https://tinyurl.com/ybyam2do

6. Tekce N, Tuncer S, Demirci M, Serim ME, Baydemic C. The effect of different drinks on the color stability of different restorative materials after one month. Restor Dent Endod. 2015; 40: 255-261. Ref.: https://tinyurl.com/yb2b8rrt

7. Kramer N, Reinelt C, Frankenberg R. Ten-year clinical performance of posterior resin composite restorations. J Adhes Dent. 2015; 17: 433-441. Ref.: https://tinyurl.com/yavgk2aq

8. Acar O, Yilmaz B, Altintas SH, Chandrasekaran I, Johnston WM. Color stainability of CAD/CAM and nanocomposite resin materials. J Prosthet Dent. 2015; 115: 71-75. Ref.: https://tinyurl.com/y9agwyno

9. Kumari RV, Nagaraj H, Siddaraju K, Poluri RK. Evaluation of the effect of surface polishing, oral beverages and food colorants on color stability and surface roughness of nanocomposite resins. $J$ Int Oral Health. 2015; 7: 63-70. Ref.: https://tinyurl.com/y9gtdf2v 
10. Yildiz E, Sirin Karaarslan E, Simsek M, Ozsevik AS, Usumez A. Color stability and surface roughness of polished anterior restorative materials. Dent Mat J. 2015; 34: 629-639. Ref.: https://tinyurl.com/yd4ceh4j

11. Heinze SD, Rousson V, Hickel R. Clinical effectiveness of direct anterior restorations-a metaanalysis. Dent Mater. 2015; 31: 481-495. Ref.: https://tinyurl.com/yd4wpkc9

12. Bezgin T, Ozer L, Tulga Oz F, Ozcan P. Effect of toothbrushing on color changes of esthetic restorative materials. J Esthet Restor Dent. 2015; 27: S65-73. Ref.: https://tinyurl.com/yauvqsca

13. Karaman E, Tuncer D, Firat E, Ozdemir OS, Karahan S. Influence of different staining beverages on color stability, surface roughness and microhardness of silorane and methacrylate-based composite resin. J Contemp dent Pract. 2014; 15: 319-325. Ref.: https://tinyurl.com/ybkjgr9d

14. Tan BL, Yap AU, Ma HN, Chew J, Tan WJ. Effect of beverages on color translucency of new toothcolored restoratives. Oper Dent. 2015; 40: E56-65. Ref.: https://tinyurl.com/y83nbdcd

15. Harorli OT, Barutcigil C. Color recovery effect of commercial mouth rinses on a discolored composite. J Esthet Restor Dent. 2014; 26: 256-263. Ref.: https://tinyurl.com/yblz24yq

16. Ardu S, Braut V, Uhac I, Benbachir N, Feilzer AJ, et al. Influence of mechanical and chemica degradation on surface gloss of resin composite materials. Am J Dent. 2009; 5: 264-268. Ref.: https://tinyurl.com/y9jayaek

17. Lefever D, Perakis N, Roig M, Krejci I, Ardu S. The effect of toothbrushing on surface gloss of resin composites. Am J Dent. 2012; 1: 54-58. Ref.: https://tinyurl.com/y8fuabqf

18. Ardu S, Braut V, Gutemberg D, Krejci I, Dietschi D, et al. A long-term laboratory test on staining susceptibility of esthetic composite resin materials. Quintessence Int. 2010; 41: 695-702. Ref.: https://tinyurl.com/yc5cpjvb

19. Ferracane JL. Correlation between hardness and degree of conversion during the setting reaction of unfilled dental restorative resins. Dent Mater. 1985; 1: 11-14. Ref.: https://tinyurl.com/y7jvvb97

20. Ferracane JL, Moser JB, Greener EH. Ultraviolet light-induced yellowing of dental restorative resins. J Prosthet Dent. 1985; 54: 483-487. Ref.: https://tinyurl.com/y8qn6zt5

21. Douglas WH, Craig RG. Resistance to extrinsic stains by hydrophobic composite resin systems. $J$ Dent Res. 1982; 61: 41-43. Ref.: https://tinyurl.com/yafdnd8y

22. Satou N, Khan AM Matsumae I, Satou J Shintani H. In vitro color change of composite-based resins Dent Mater. 1989; 5: 384-387. Ref.: https://tinyurl.com/yb5fezso

23. Waerhaug J. Temporary restorations: advantages and disadvantages. Dent Clin North Am. 1980; 24 305-316. Ref.: https://tinyurl.com/yavlsaey

24. Pipko JD, El-Sadeek M. An in vitro investigation of abrasion and staining of dental resins. J Dent Res. 1972; 51: 689-705. Ref.: https://tinyurl.com/yc9bvu7f

25. Nordbo H, Attramadal A, Eriksen HM. Iron discoloration of acrylic resin exposed to chlorhexidine or tannic acid: a model study. J Prosthet Dent. 1983; 49: 126-129. Ref.: https://tinyurl.com/yd54j9yx

26. Um CM, Ruyter IE. Staining of resin-based veneering materials with coffee and tea. Quintessence Int. 1991; 22: 377-386. Ref.: https://tinyurl.com/yb4kjf59

27. Scotti R, Mascellani SC, Forniti F. The in vitro color stability of acrylic resin for provisional restorations. Int J Prosthodont. 1997; 10: 164-168. Ref.: https://tinyurl.com/yadvs4ch

28. Asmussen E, Hansen EK. Surface discoloration of restorative resins in relation to surface softening and oral hygiene. Scandinavian J Dent Res. 1986; 94: 174-177. Ref.: https://tinyurl.com/yc42b7fw

29. Bolt RA, Bosh JJ, Coops JC. Influence of window size in small-window colour measurement, particularly of teeth. Phys Med Biol. 1994; 39: 1133-1142. Ref.: https://tinyurl.com/y7zwpwhg

30. Hachiya Y, Iwaku M, Hosoda H, Fusayama T. Relation of finish to discoloration of composite resins. J Prosthet Dent. 1984; 52: 811-814. Ref.: https://tinyurl.com/ycb9x7hr

31. Shintani H, Satou J, Satou N, Hayashira H, Inoue T. Effects of various finishing methods on staining and accumulation of Streptococcus mutans HS-6 on composite resins. Dent Mater. 1985; 1: 225227. Ref.: https://tinyurl.com/y7pxpejp

32. Van Groeningen G, Jonnebloed W, Arends J. Composite degradation in vivo. Dent Mater. 1986; 2 225-227. Ref.: https://tinyurl.com/y7levesw

33. Abu-Bakr N, Han L, Okamoto A, Iwaku M. Color stability of compomer after immersion in various media. J Esthet Dent. 2000; 12: 258-263. Ref.: https://tinyurl.com/yc9fhwty 
34. Fay RM, Walker CS, Power JM. Discoloration of a compomer by stains. J Great Houst Dent Soc. 1998; 69: 12-13. Ref.: https://tinyurl.com/yaf643hs

35. Fay RM, Walker CS, Power JM. Color stability of hybrid ionomers after immersion in stains. Am J Dent. 1998; 11: 71-72.

36. Reis AF, Giannini M, Lovadino JR, Ambrosano JM. Effects of various finishing systems on the surface roughness and staining susceptibility of packable composite resins. Dent Mater. 2003; 19 : 12-18. Ref.: https://tinyurl.com/ybp4y48u

37. Chan KC, Fuller JL, Hormati AA. The ability of foods to stain two composite resins. J Prosthet Dent. 1980; 43: 542-545. Ref.: https://tinyurl.com/ycsjozkq

38. Gross MD, Moser JB. A colorimetric study of coffee and tea staining of four composite resins. J Oral Rehabil. 1977; 4: 311-322. Ref.: https://tinyurl.com/yc6t3lko

39. Luce MS, Campbell CE. Stain potential of four microfilled composites. J Prosthet Dent. 1988; 60 : 151-154. Ref.: https://tinyurl.com/yd3psgcz

40. Ardu S, Duc O, Di Bella E, Krejci I. Color stability of recent composite resins. Odontology. 2016; 150: 29-35. Ref.: https://tinyurl.com/y83xd4l2

41. Park SH, Noh BD, Ahn HJ, Kim HK. Celluloid strip-finished versus polished composite surface: difference in surface discoloration in microhybrid composites. J Oral Rehabil. 2004; 31: 62-66. Ref.: https://tinyurl.com/ydchwpyf

42. Garoushi S, Lassila L, Hatem M, Shembesh M, Baady L, et al. Influence of staining solutions and whitening procedures on discoloration of hybrid composite resins. Acta Odontol Scand. 2013; 71: 144-150. Ref.: https://tinyurl.com/y7udckyw

43. Borges $A B$, Marsilio AL, Pagani $C$, Rodrigues JR. Surface roughness of packable composite resins polished with various systems. J Esthet Restor Dent. 2004; 16: 42-47. Ref.: https://tinyurl.com/yb9tfwh2

44. Gönülol N, Yilmaz F. The effects of finishing and polishing techniques on surface roughness and color stability of nanocomposites. J Dent. 2012; 40: e64-70. Ref.: https://tinyurl.com/ydf3lzpk

45. Nasim I, Neelakantan P, Sujeer R, Subbarao C. Colour stability of microfilled, microhybrid and nanocomposite resins-An in vitro study. J Dent. 2010;38: 137-142. Ref.: https://tinyurl.com/ybnjokg2

46. Catelan A, Briso AL, Sundfeld RH, Goiato MC, dos Santos PH. Color stability of sealed composite resin restorative materials after ultraviolet artificial aging and immersion in staining solutions. $J$ Prosthet Dent. 2011; 105: 236-241. Ref.: https://tinyurl.com/y8mp8on5

47. Nasu $T$, Minesaki $Y$, Ito $S$, Kajihara $H$, Muraguchi $K$, et al. Color stability of new composite denture tooth containing reactive organic composite filler. Jap Prosthodont Soc. 2004; 48: 242-250.

48. Ertas $E$, Güler $A U$, Yècel $A C$, Köprül $H$, Güler E. Color stability of resin composites after immersion in different drinks. Dent Mater. 2006; 25: 371-376. Ref.: https://tinyurl.com/y8h77sjt

49. Leloup G, Holvoet PE, Bebelman S, Devaux J. Raman scattering determination of the depth of cure of light-activated composites: influence of different clinically relevant parameters. J Oral Rehab. 2002 29: 510-515. Ref.: https://tinyurl.com/ybox5p7b

50. Ardu S, Gutemberg D, Krejci I, Feilzer AJ, Di Bella E, et al. Influence of water sorption on resin composite color and color variation amongst various composite brands with identical shade code: an in vitro evaluation. J Dent. 2011; 39: e37-44. Ref.: https://tinyurl.com/y8p3bnpk

51. Alharbi A, Ardu S, Bortolotto T, Krejci I. Stain susceptibility of composite and ceramic CAD/CAM blocks versus direct resin composites with different resinous matrices. Odontology. 2017; 105: 162169. Ref.: https://tinyurl.com/yb6m3gyo

52. Ardu S, Braut V, Di Bella E, Lefever D. Influence of background on natural tooth colour coordinates: an in vivo evaluation. Odontology. 2014; 102: 267-271. Ref.: https://tinyurl.com/y992ygkq 